This item was submitted to Loughborough's Research Repository by the author.

Items in Figshare are protected by copyright, with all rights reserved, unless otherwise indicated.

\title{
Sleep-related vehicle crashes on low speed roads
}

PLEASE CITE THE PUBLISHED VERSION

http://dx.doi.org/10.1016/j.aap.2016.12.002

PUBLISHER

(c) Elsevier

VERSION

AM (Accepted Manuscript)

PUBLISHER STATEMENT

This work is made available according to the conditions of the Creative Commons Attribution-NonCommercialNoDerivatives 4.0 International (CC BY-NC-ND 4.0) licence. Full details of this licence are available at: https://creativecommons.org/licenses/by-nc-nd/4.0/

\section{LICENCE}

CC BY-NC-ND 4.0

\section{REPOSITORY RECORD}

Filtness, Ashleigh, Kerry A. Armstrong, Angela Watson, and Simon S. Smith. 2019. "Sleep-related Vehicle Crashes on Low Speed Roads". figshare. https://hdl.handle.net/2134/23595. 


\section{Sleep-related vehicle crashes on low speed roads}

2

4 Queensland University of Technology (QUT), Centre for Accident Research and Road Safety-

5 Queensland (CARRS-Q), 130 Victoria Park Road, Kelvin Grove, QLD, Australia

$6 \quad *$ Corresponding author:

7 Ashleigh Filtness, Ph.D.

8 Present address: Loughborough Design School, Loughborough University, Leicestershire, LE11 3TU, 9 UK

10 Tel: +44 1509226934

11 Email: A.J.Filtness@lboro.ac.uk

\section{Highlights}

- $10 y$ of police reported sleep-related (SR) crashes were analysed: high vs low speed; low speed SR vs not-SR.

- Young (16-24y) males are overrepresented in SR crashes.

- Low speed SR crashes have similar characteristics to high speed SR crashes.

- SR crashes on low speed roads have more severe outcomes than not-SR crashes.

- Driver education should be broadened, including implications for driver sleepiness on low speed roads. 
Background: Very little is known about the characteristics of sleep related (SR) crashes occurring on

3

4

5

6

7

low speed roads compared with current understanding of the role of sleep in crashes occurring on

high speed roads e.g. motorways. To address this gap, analyses were undertaken to identify the differences and similarities between (1) SR crashes occurring on roads with low ( $\leq 60 \mathrm{~km} / \mathrm{h}$ ) and high $(\geq 100 \mathrm{~km} / \mathrm{h}$ ) speed limits, and (2) SR crashes and not-SR crashes occurring on roads with low speed limits.

Method: Police reports of all crashes occurring on low and high speed roads over a ten year period between 2000 and 2009 were examined for Queensland, Australia. Attending police officers identified all crash attributes, including 'fatigue/fell asleep', which indicates that the police believe the crash to have a causal factor relating to falling asleep, sleepiness due to sleep loss, time of day, or fatigue. Driver or rider involvement in crashes was classified as SR or not-SR. All crash-associated variables were compared using Chi-square tests (Cramer's V = effect size). A series of logistic regression were performed, with driver and crash characteristics as predictors of crash category. A conservative alpha level of .001 determined statistical significance.

Results: There were 440,855 drivers or riders involved in a crash during this time; 6,923 (1.6\%) were attributed as SR. SR crashes on low speed roads have similar characteristics to those on high speed roads with young (16-24y) males consistently over represented. SR crashes on low speed roads are noticeably different to not-SR crashes in the same speed zone in that male and young novice drivers are over represented and outcomes are more severe. Of all the SR crashes identified, $41 \%$ occurred on low speed roads.

Conclusion: SR crashes are not confined to high speed roads. Low speed SR crashes warrant specific investigation because they occur in densely populated areas, exposing a greater number of people to risk and have more severe outcomes than not-SR crashes on the same low speed roads. 
1 Key words: driver sleepiness, driver drowsiness, driver fatigue, road crash, police data

\section{Introduction}

3 Sleep-related (SR) crashes are a road safety problem the world over (Åkerstedt, 2000). Drivers who

4 are sleepy are at an almost six fold increase in the odds of having an injury involved crash (Herman

5 et al. 2014). It has been demonstrated that SR crashes are prevalent on high speed motorways (e.g.

6 Connor et al. 2002, Philip et al. 2014). Reflecting this, the majority of driver sleepiness research has

7 been targeted at understanding and mitigating SR incidents during motorway driving (e.g. Philip et

8 al. 2005, Filtness et al. 2012, Hallvig et al. 2013). However, self-reported experience by drivers of SR

9 driving incidents suggest that approximately $25 \%$ of SR incidents occur on roads with a speed limit of

$10 \leq 50 \mathrm{~km} / \mathrm{h}(31 \mathrm{mph})$, with a further $30 \%$ occurring on roads with speed limits between 50 and $80 \mathrm{~km} / \mathrm{h}$

11 (31-50mph) (Armstrong et al. 2013). To date, little attempt has been made to specifically investigate

12 these low speed SR crashes therefore it is unknown how these differ from either not-SR crashes of a similar speed or high speed SR crashes.

Driver sleepiness is common, with $9 \%$ of French drivers $(n=35,000)$ reporting being so sleepy that they have to stop driving at least once per month (Philip et al. 2010), and 8\% of Norwegian drivers reporting having fallen asleep while driving in the past month (Sagberg 1999). Experimental investigations using driving simulators and on-road driving protocols have demonstrated that sleepy drivers have impaired driving performance in terms of increased number of out of lane events (e.g. Horne and Reyner 1996), variability in lane positioning (e.g. Anund et al. 2008; Forsman et al., 2013) and variability in speed control (e.g. Matthews et al. 2012). These investigations (and many others) have provided important insight into driver sleepiness, but in each case the influence of sleepiness on driving performance was examined in high speed zone motorways or high speed zone scenarios meaning that it is unknown whether findings can be inferred to low speed driving conditions or not. Furthermore, education and awareness campaigns have sought to highlight the dangers of sleepiness associated with long distance driving, with many strategies targeted towards motorway 
1

2

3

4

5

6

7

8

9

driving e.g. road signs advising drivers to take a break, while driver sleepiness in low speed zones is largely overlooked.

The focus of research attention towards high speed zones is arguably warranted as analyses of crash data demonstrate SR crashes to be most common in high speed zones, with driving on a highway a leading predictor of SR crash (Philip et al. 2014). However, using such a focused approach to both education and awareness campaigns and targeted maximum driving hours requirements for heavy vehicles, could result in drivers believing that driver sleepiness is a problem isolated to high speed motorways. Therefore, it is possible that drivers may ignore or overlook the danger during city driving. Similarly, targeted interventions may be missing some important aspects related to driver sleepiness on low speed roads.

Understanding whether low speed SR crashes differ from high speed SR crashes is necessary in determining whether those road safety countermeasures applied in high speed environments (e.g. driver sleepiness advise warning signs) may also be relevant for low speed environments. This is particularly important as many drivers report having experienced a SR incident on a low speed road and any SR incidents (regardless of speed zone) are most common when commuting to and from work (Armstrong et al. 2013). Highly dynamic urban driving requires quick responses and quick decision making in a complex and often shared road environment. Both reaction time (Belenky et al. 2003) and flexibility of decision making in cognitive tasks (Harrison and Horne 2000) are known to be impaired by sleepiness, suggesting that sleepy drivers may have impaired responses to safety critical events. Low speed roads are predominantly located in highly populated areas exposing a greater number of people to risk from a sleepy driver than the equivalent driver on a high speed road. However, there is a dearth of literature exploring sleep related impairment in an urban driving context. A first step in understanding the impact of sleepiness on low speed driving performance is to examine its consequence through analysis of crash data from low speed zones. 
1 The objective of the current work was to quantify the characteristics of SR crashes occurring on low

$2(\leq 60 \mathrm{~km} / \mathrm{h}$; approximately $\leq 37 \mathrm{mph})$ speed roads in comparison to both high ( $\geq 100 \mathrm{~km} / \mathrm{h}$;

3 approximately $\geq 62 \mathrm{mph}$ ) speed road SR crashes and to not-SR crashes on the same low speed areas.

4 Both vehicle operator and crash characteristics from police crash report data were considered.

5 Statistical analysis sought to identify similarities between high and low speed sleep crashes and differences between SR and not-SR crashes on low speed roads.

\section{Methods}

\section{$8 \quad 2.1 \quad$ Crash data}

9 Queensland (Australia) police reports for crashes occurring on low $(\leq 60 \mathrm{~km} / \mathrm{h})$ and high $(\geq 100 \mathrm{~km} / \mathrm{h})$ speed roads between $1^{\text {st }}$ January 2000 and $31^{\text {st }}$ December 2009 were examined. Ten years of crash data provided sufficient scope for identifying general trends and permitted meaningful comparisons between SR and not-SR crashes. Police crash reports detail those crashes which occur on a public road, and where: a person was killed or injured, a vehicle towed, or greater than $\$ 2500$ of damage to property other than vehicles was incurred. Crashes resulting from medical conditions and deliberate acts were excluded. Police crash reports detail vehicle operator characteristics and crash characteristics as well as crash causal factors (multiple causal factors may be identified for each crash); these are all identified by the reporting Queensland Police Services (QPS) officer. Serious crashes (fatal or serious injury) are attended by the Forensic Crash Investigation unit, where specially trained officers will seek detailed information about the circumstances during and prior to the crash which can include the extent of prior sleep. All non-serious crashes are attended by regular enforcement officers.

All crash reports where the contributory factor "fatigue/fell asleep" was noted were classified as SR. In assigning this contributory factor the crash database does not distinguish between crashes due to 
1

2

3

4

5

6

7

8

9

falling asleep while driving, sleepiness due to sleep loss, time of day, duration of driving or fatigue etc., although these may have been considered by the attending officer.

In order to include driver characteristics as variables of interest the main unit of analysis was the drivers or riders involved in crashes during the period, rather than crashes per se. Crash reports were grouped into four crash categories:

1. Sleep-related on $\geq 100 \mathrm{~km} / \mathrm{h}$ speed roads $(\mathrm{SR}-\mathrm{H})$

2. Not sleep-related on $\geq 100 \mathrm{~km} / \mathrm{h}$ speed roads (Not SR-H)

3. Sleep-related on $\leq 60 \mathrm{~km} / \mathrm{h}$ speed roads (SR-L)

4. Not sleep-related on $\leq 60 \mathrm{~km} / \mathrm{h}$ speed roads (Not SR-L)

This work extends a previous investigations which usedsub-sets of this sleep-related crash data (Armstrong et al. 2008, Filtness et al. in press). Within Queensland, local government authorities retrospectively apply a proxy definition to police crash data in order to identify sleep-related crashes which were potentially missed by the police. This is a desk based exercise applied externally from police investigations and is not considered in the current work. All presented analysis is for crash data as recorded by the police.

\subsection{Statistical Analysis}

For each variable, comparison was made between category 1 and 3 and category 3 and 4 .

Categorical data were analysed using Chi-square ( $\chi 2)$ tests with Cramer's V $(\phi c)$ as an estimate of effect size. Post-hoc analyses were undertaken within each variable using the adjusted standardised residual statistic (ê).

A multivariate analysis consisting of a series of logistic regressions were performed, with driver/crash characteristics as predictors of crash category. The crash characteristics are defined by the Queensland Department of Transport and Main Roads (2014). In the interests of parsimony, only statistically significant predictors at the bivariate level were included in the model. A significance 
1

2 conducted using IBM SPSS 19.0 statistical software.

\section{Results}

5 Overall, there were 440,855 vehicle operators (drivers and riders) involved in crashes on Queensland roads with speed zones of interest during the time period. Of these crashes 6,923 (1.6\%) were considered by the police to be sleep-related, with $41.1 \%$ of these occurring in low speed zones (see Table 1 for breakdown by speed zone).

Table 1: Number and proportion of sleep-related crashes for $\leq 60 \mathrm{~km} / \mathrm{h}$ speed zones and $\geq 100 \mathrm{~km} / \mathrm{h}$ speed zones

\begin{tabular}{lll}
\hline & $\leq 60 \mathrm{~km} / \mathrm{h}$ speed roads & $\geq 100 \mathrm{~km} / \mathrm{h}$ speed roads \\
\hline All drivers or riders & 306,300 & 65,205 \\
Fatigue/fell asleep (\%) & $2,408(0.7 \%)$ & $3,449(5.3 \%)$ \\
\hline
\end{tabular}

\subsection{Vehicle operator characteristics}

\subsubsection{Low speed sleep-related crashes vs high speed sleep-related crashes}

The proportion of crashes including each vehicle operator variable of interest is displayed in Table 2 .

Compared with SR-H crashes, SR-L crashes involved a lower percentage of heavy vehicles $\left[\chi^{2}(3)=\right.$ 74.06, $\left.p<.001, \phi_{c}=.11\right]$ and vehicles carrying passengers $\left[x^{2}(1)=96.77, p<.001, \phi_{c}=.13\right]$. There were no statistically significant differences based on gender $\left[\chi^{2}(1)=3.13, p=.077, \phi_{c}=.02\right]$; age group $\left[\chi^{2}(2)=14.86, p=.002, \phi_{c}=.05\right]$; licence level $\left[\chi^{2}(3)=2.57, p=.464, \phi_{c}=.02\right]$ or drink driving $\left[\chi^{2}(1)=0.01, p=.908, \phi_{c}=.0002\right]$.

\subsubsection{Low speed sleep-related crashes vs low speed not sleep-related crashes}

Considering all crashes on $\leq 60 \mathrm{~km} / \mathrm{hr}$ speed roads, a higher percentage of those drivers or riders who were involved in SR crashes were male $\left[\chi^{2}(1)=134.31, p<.001, \phi_{c}=.02\right]$; aged $16-24$ years $\left[\chi^{2}(2)=69.20, p<.001, \phi_{c}=.02\right]$; hold a provisional driver's licence or be unlicensed $\left[\chi^{2}(3)=69.49, p\right.$ 
$\left.1<.001, \phi_{c}=.02\right]$; and be over the prescribed alcohol limit $\left[\chi^{2}(1)=89.20, p<.001, \phi_{c}=.02\right]$. For those

2 drivers or riders involved in crashes on $\leq 60 \mathrm{~km} / \mathrm{hr}$ speed roads, a lower percentage of those drivers

3 whose crash circumstances were attributed to be SR were motorcyclists $\left[\chi^{2}(3)=201.46, p<.001, \phi_{c}\right.$

$4=.03]$ and a higher percentage were carrying passengers $\left[\chi^{2}(1)=96.70, p<.001, \phi_{c}=.02\right]$.

5 Table 2: Characteristics of vehicle operators involved in a crash for each crash category between $1^{\text {st }}$

6 January 2000 and $31^{\text {st }}$ December 2009

\begin{tabular}{|c|c|c|c|c|}
\hline \multirow[b]{2}{*}{ Variable } & \multicolumn{2}{|c|}{$\geq 100 \mathrm{~km} / \mathrm{hr}$ speed roads } & \multicolumn{2}{|c|}{$\leq 60 \mathrm{~km} / \mathrm{hr}$ speed roads } \\
\hline & Sleep-related & Not sleep-related & Sleep-related & Not sleep-related \\
\hline Gender & $(n=3,437)$ & $(n=60,533)$ & $(n=1,978)$ & $(n=286,112)$ \\
\hline Male & $76.8 \%$ & $69.4 \%$ & $74.7 \%$ & $61.6 \%$ \\
\hline Female & $23.2 \%$ & $30.6 \%$ & $25.3 \%$ & $38.4 \%$ \\
\hline Age & $(n=3,425)$ & $(n=60,105)$ & $(n=1,975)$ & $(n=282,685)$ \\
\hline $16-24$ & $34.5 \%$ & $25.9 \%$ & $36.5 \%$ & $28.8 \%$ \\
\hline $25-59$ & $55.0 \%$ & $63.6 \%$ & $56.2 \%$ & $60.1 \%$ \\
\hline 60 and over & $10.5 \%$ & $10.5 \%$ & $7.3 \%$ & $11.1 \%$ \\
\hline Licence Level & $(n=3,215)$ & $(n=56,932)$ & $(n=1,883)$ & $(n=273,920)$ \\
\hline Open & $70.1 \%$ & $79.6 \%$ & $69.3 \%$ & $77.3 \%$ \\
\hline Provisional & $22.2 \%$ & $14.8 \%$ & $22.3 \%$ & $16.6 \%$ \\
\hline Learner & $2.6 \%$ & $2.0 \%$ & $3.3 \%$ & $2.4 \%$ \\
\hline Unlicensed & $5.0 \%$ & $3.6 \%$ & $5.1 \%$ & $3.7 \%$ \\
\hline Vehicle Type & $(n=3,449)$ & $(n=61,756)$ & $(n=2,408)$ & $(n=303,892)$ \\
\hline Car & $88.0 \%$ & $83.3 \%$ & $95.3 \%$ & $85.5 \%$ \\
\hline Motorcycle & $0.5 \%$ & $4.4 \%$ & $0.4 \%$ & $4.4 \%$ \\
\hline Heavy Vehicle & $8.2 \%$ & $9.2 \%$ & $3.8 \%$ & $4.1 \%$ \\
\hline Other & $3.3 \%$ & $3.1 \%$ & $0.6 \%$ & $6.0 \%$ \\
\hline No. of occupants & $(n=3,434)$ & $(n=61,230)$ & $(n=1,985)$ & $(n=290,975)$ \\
\hline One & $67.6 \%$ & $64.8 \%$ & $79.8 \%$ & $68.1 \%$ \\
\hline More than one & $32.4 \%$ & $35.2 \%$ & $20.2 \%$ & $31.9 \%$ \\
\hline $\begin{array}{l}\text { Driver over alcohol } \\
\text { limit }\end{array}$ & $(n=3,449)$ & $(n=61,756)$ & $(n=2,408)$ & $(n=303,892)$ \\
\hline Yes & $7.7 \%$ & $4.5 \%$ & $7.8 \%$ & $4.2 \%$ \\
\hline No & $92.3 \%$ & $95.5 \%$ & $92.2 \%$ & $95.8 \%$ \\
\hline
\end{tabular}

\section{$7 \quad 3.2 \quad$ Crash Characteristics}

$8 \quad$ 3.2.1 Low speed sleep-related crashes vs high speed sleep-related crashes

9 The proportion of each crash characteristic of interest is displayed in Table 3. Comparing SR-L and

10 SR-H revealed a statistically significant difference in crash severity $\left[\chi^{2}(4)=261.55, p<.001, \phi_{c}=.19\right]$.

11 Specifically, SR-L crashes had a lower proportion than expected of serious crashes (i.e., fatal or requiring hospitalisation). Also, SR-L crashes had a lower proportion than expected of sideswipe 
$1 \quad\left[\chi^{2}(1)=17.07, p<.001, \phi_{c}=.05\right]$ and overturned $\left[\chi^{2}(1)=578.19, p<.001, \phi_{c}=.31\right]$ crashes compared

2 with SR-H crashes. Conversely, SR-L crashes had a greater proportion than expected of hitting an

3 object $\left[\chi^{2}(1)=138.90, p<.001, \phi_{c}=.15\right]$, rear-end $\left[\chi^{2}(1)=74.39, p<.001, \phi_{c}=.11\right]$, and angle $\left[\chi^{2}(1)=\right.$

4

5

6

7

8

9

$\left.152.27, p<.001, \phi_{c}=.16\right]$ crashes occurring at dusk, dawn, or in darkness $\left[\chi^{2}(2)=39.81, p<.001, \phi_{c}=\right.$ $.08]$, between $10 \mathrm{pm}$ and $6 \mathrm{am}\left[\chi^{2}(3)=40.68, p<.001, \phi_{c}=.08\right]$, at intersections $\left[\chi^{2}(1)=661.10, p<\right.$ $\left..001, \phi_{c}=.34\right]$, and with traffic control $\left[x^{2}(1)=485.35, p<.001, \phi_{c}=.29\right]$. There were no statistically significant differences for SR crashes in the different speed zones on atmospheric conditions $\left[x^{2}(3)=\right.$ $\left.21.01, p=.002, \phi_{c}=.06\right]$, whether it was a head-on crash $\left[\chi^{2}(1)=8.12, p=.004, \phi_{c}=.04\right]$, or day of week $\left[\chi^{2}(1)=0.01, p=.927, \phi_{c}=.001\right]$.

\subsubsection{Low speed sleep-related crashes vs low speed not sleep-related crashes}

Considering all crashes in low speed zones, there was a statistically significant difference in crash severity $\left[\chi^{2}(4)=70.41, p<.001, \phi_{c}=.02\right]$ between SR-L and not SR-L crashes. Specifically, SR-L crashes had a higher proportion than expected of serious crashes (i.e., fatal or hospitalisation) than did not SR-L crashes. Also, SR-L crashes had a greater proportion than expected of hit object $\left[\chi^{2}(1)=\right.$ 4972.72, $\left.p<.001, \phi_{c}=.13\right]$, head-on $\left[\chi^{2}(1)=193.46, p<.001, \phi_{c}=.03\right]$, and overturned $\left[\chi^{2}(1)=14.72\right.$ $\left.p<.001, \phi_{c}=.01\right]$ crashes, compared with not SR-L. There were also a greater proportion of SR-L crashes occurring at dusk, dawn, or in darkness $\left[\chi^{2}(2)=863.51, p<.001, \phi_{c}=.05\right]$, between 10pm and 6am $\left[\chi^{2}(3)=3399.02, p<.001, \phi_{c}=.10\right]$, and on weekends $\left[\chi^{2}(1)=246.07, p<.001, \phi_{c}=.03\right]$ compared with not SR-L. Conversely SR-L had a lower proportion than expected of rear-end $\left[\chi^{2}(1)=\right.$ $\left.371.44, p<.001, \phi_{c}=.04\right]$, angle $\left[\chi^{2}(1)=1238.42, p<.001, \phi_{c}=.06\right]$, and sideswipe $\left[\chi^{2}(1)=21.50, p<\right.$ $\left..001, \phi_{c}=.01\right]$ crashes in raining conditions $\left[\chi^{2}(3)=35.52, p<.001, \phi_{c}=.01\right]$, at intersections $\left[\chi^{2}(1)=\right.$ 772.63, $\left.p<.001, \phi_{c}=.05\right]$, with traffic control $\left[\chi^{2}(1)=524.32, p<.001, \phi_{c}=.04\right]$ compared with not SR-L. 
1 Table 3: Characteristics of crashes for each crash category between $1^{\text {st }}$ January 2000 and $31^{\text {st }}$

2 December 2009

\begin{tabular}{|c|c|c|c|c|}
\hline \multirow[b]{2}{*}{ Variable } & \multicolumn{2}{|c|}{$\geq 100 \mathrm{~km} / \mathrm{hr}$ speed roads } & \multicolumn{2}{|c|}{$\leq 60 \mathrm{~km} / \mathrm{hr}$ speed roads } \\
\hline & Sleep-related & Not sleep-related & Sleep-related & Not sleep-related \\
\hline Crash Severity & $(n=3,449)$ & $(n=61,756)$ & $(n=2,408)$ & $(n=303,892)$ \\
\hline Fatal/Hospitalisation & $43.5 \%$ & $31.8 \%$ & $27.3 \%$ & $21.4 \%$ \\
\hline Medical Treatment & $18.5 \%$ & $20.9 \%$ & $21.0 \%$ & $25.0 \%$ \\
\hline Minor Injury & $9.9 \%$ & $11.1 \%$ & $11.5 \%$ & $14.8 \%$ \\
\hline PDO & $28.2 \%$ & $36.2 \%$ & $40.2 \%$ & $38.8 \%$ \\
\hline Intersection & $(n=3,449)$ & $(n=61,756)$ & $(n=2,408)$ & $(n=303,892)$ \\
\hline No & $96.5 \%$ & $85.1 \%$ & $73.5 \%$ & $44.9 \%$ \\
\hline Yes & $3.5 \%$ & $14.9 \%$ & $26.5 \%$ & $55.1 \%$ \\
\hline Traffic control & $(n=3,449)$ & $(n=61,756)$ & $(n=2,408)$ & $(n=303,892)$ \\
\hline No & $99.4 \%$ & $94.9 \%$ & $84.8 \%$ & $61.7 \%$ \\
\hline Yes & $0.6 \%$ & $5.1 \%$ & $15.2 \%$ & $38.3 \%$ \\
\hline Lighting conditions & $(n=3,449)$ & $(n=61,756)$ & $(n=2,408)$ & $(n=303,892)$ \\
\hline Daylight & $53.5 \%$ & $70.1 \%$ & $46.0 \%$ & $72.5 \%$ \\
\hline Dawn/Dusk & $8.6 \%$ & $6.6 \%$ & $7.8 \%$ & $5.0 \%$ \\
\hline Darkness & $37.9 \%$ & $23.3 \%$ & $46.2 \%$ & $22.5 \%$ \\
\hline $\begin{array}{l}\text { Atmospheric } \\
\text { conditions }\end{array}$ & $(n=3,449)$ & $(n=61,756)$ & $(n=2,408)$ & $(n=303,892)$ \\
\hline Clear & $93.1 \%$ & $83.1 \%$ & $92.1 \%$ & $88.6 \%$ \\
\hline Raining & $5.4 \%$ & $15.1 \%$ & $7.3 \%$ & $11.1 \%$ \\
\hline Smoke/Dust & $0.1 \%$ & $0.6 \%$ & $0.0 \%$ & $0.1 \%$ \\
\hline Fog & $1.5 \%$ & $1.2 \%$ & $0.5 \%$ & $0.3 \%$ \\
\hline Crash type & $(n=3,449)$ & $(n=61,756)$ & $(n=2,408)$ & $(n=303,892)$ \\
\hline Hit object & $56.7 \%$ & $26.6 \%$ & $71.8 \%$ & $17.0 \%$ \\
\hline Other & $43.3 \%$ & $73.4 \%$ & $28.2 \%$ & $83.0 \%$ \\
\hline Rear-end & $5.2 \%$ & $26.4 \%$ & $11.4 \%$ & $29.3 \%$ \\
\hline Other & $94.8 \%$ & $73.6 \%$ & $88.6 \%$ & $70.7 \%$ \\
\hline Head-on & $7.6 \%$ & $4.9 \%$ & $5.7 \%$ & $1.8 \%$ \\
\hline Other & $92.4 \%$ & $95.1 \%$ & $94.3 \%$ & $98.2 \%$ \\
\hline Angle & $1.0 \%$ & $10.9 \%$ & $6.9 \%$ & $42.4 \%$ \\
\hline Other & $99.0 \%$ & $89.1 \%$ & $93.1 \%$ & $57.6 \%$ \\
\hline Sideswipe & $4.3 \%$ & $10.0 \%$ & $2.3 \%$ & $4.2 \%$ \\
\hline Other & $95.7 \%$ & $90.0 \%$ & $97.7 \%$ & $95.8 \%$ \\
\hline Overturned & $24.4 \%$ & $14.4 \%$ & $1.6 \%$ & $0.9 \%$ \\
\hline Other & $75.6 \%$ & $85.6 \%$ & $98.4 \%$ & $99.1 \%$ \\
\hline Day of week & $(n=3,449)$ & $(n=61,756)$ & $(n=2,408)$ & $(n=303,892)$ \\
\hline Monday - Friday & $63.2 \%$ & $72.9 \%$ & $63.3 \%$ & $76.8 \%$ \\
\hline Saturday - Sunday & $36.8 \%$ & $27.1 \%$ & $36.7 \%$ & $23.2 \%$ \\
\hline Time of day & $(n=3,449)$ & $(n=61,756)$ & $(n=2,408)$ & $(n=303,892)$ \\
\hline $10 \mathrm{pm}$ to $6 \mathrm{am}$ & $38.9 \%$ & $12.3 \%$ & $45.7 \%$ & $9.9 \%$ \\
\hline $6 a m$ to $2 p m$ & $33.2 \%$ & $43.6 \%$ & $31.1 \%$ & $42.9 \%$ \\
\hline $2 p m$ to $4 p m$ & $14.0 \%$ & $14.3 \%$ & $9.6 \%$ & $15.7 \%$ \\
\hline $4 \mathrm{pm}$ to $10 \mathrm{pm}$ & $13.9 \%$ & $29.8 \%$ & $13.6 \%$ & $31.6 \%$ \\
\hline
\end{tabular}




\section{$1 \quad 3.3 \quad$ Multivariate analyses}

2 Two sets of multivariate analysis were undertaken. First SR-H vs SR-L and second SR-L vs not SR-L

3 crashes. Table 4 outlines all the odds ratios, confidence intervals, and significance level for each

$4 \quad$ variable in each comparison.

\section{$5 \quad$ 3.3.1 Low speed sleep-related crashes vs. high speed sleep-related crashes}

6 With all variables included in the logistic regression, the model was statistically significant, $\chi^{2}(30)=$ $7 \quad 1498.75, p<.001$ (Nagelkerke $\mathrm{R}^{2}=.36$ ).

8 The presence of intersections and traffic control had greater odds of being a SR-L crash compared to

9 a SR-H crash. In contrast, heavy vehicles, carrying passengers, serious outcome and vehicle

10 overturned had lower odds of being a SR-L crash compared to a SR-H crash. There was no difference

11 between SR crashes in either speed zone for any other factor.

\subsubsection{Low speed sleep-related crashes vs low speed not sleep-related crashes}

With all variables in the logistic regression, the model was statistically significant, $\chi^{2}(30)=4705.89, p$

$<.001$ (Nagelkerke $\mathrm{R}^{2}=.22$ ).

- Hit object crash,

- Rear-end,

- Head-on,

- Sideswipe and

- Overturned. 
1

2

3

4

5

6

7

8

9

10

Age, presence of traffic control, and angle of crash did not differ between SR-L and not SR-L. 
1 Table 4: Logistic regression odds ratios, confidence intervals, and significance level for each variable 2 compared between SR-L vs SR-H and SR-L vs Not SR-L.

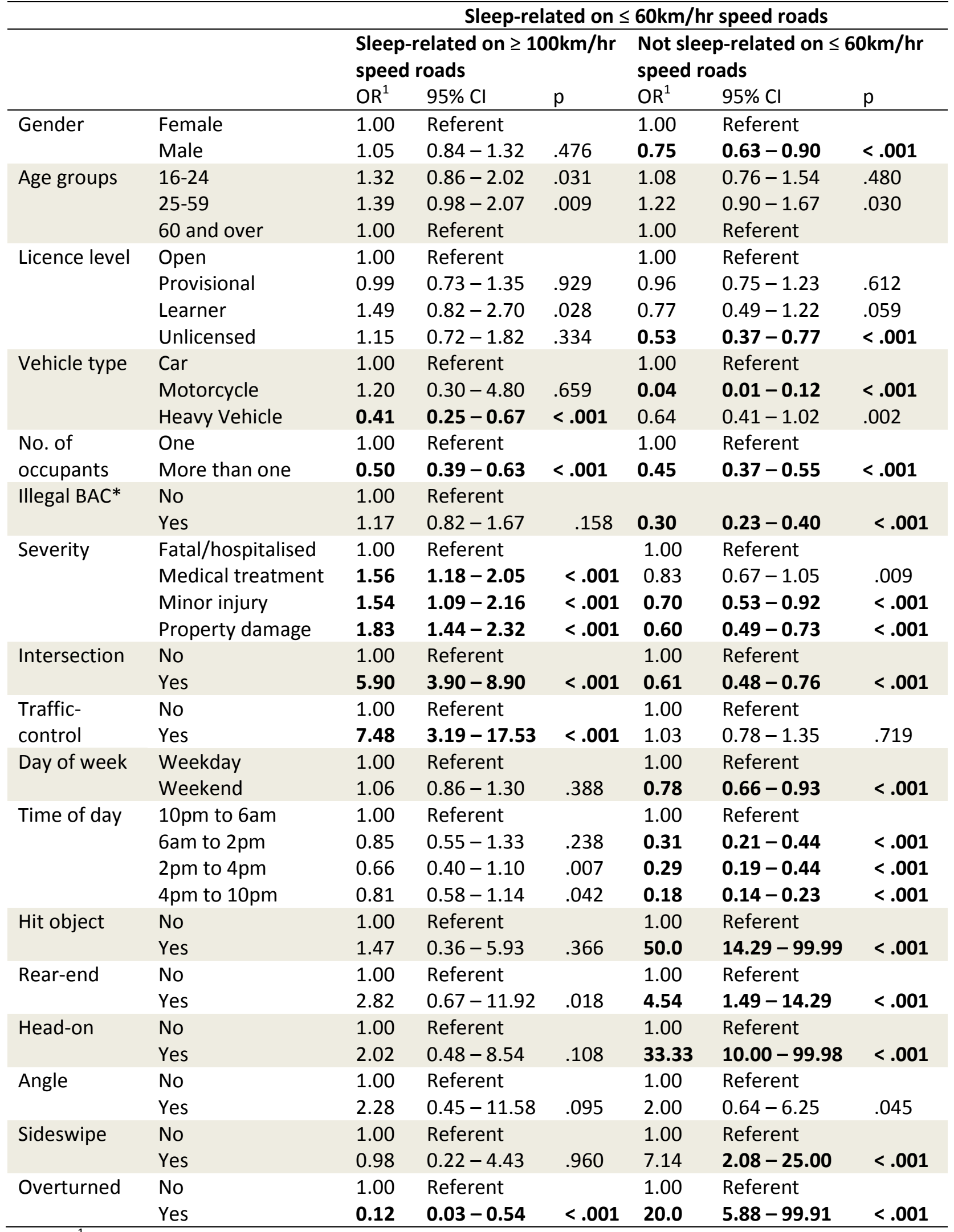

$3 \quad{ }^{1}$ Adjusted odds ratios

4 *Illegal $\mathrm{BAC}=>0.049$ for Open licence holders, $>0.00$ for provisional licence holders

5 Statistically significant results are in bold 
1

2 The current work considered all the crashes reported to the police on high speed $(\geq 100 \mathrm{~km} / \mathrm{h})$ and 3

4

\section{Discussion}

low speed $(\leq 60 \mathrm{~km} / \mathrm{h})$ roads, over a 10 year period. Results demonstrate that SR crashes are not confined to high speed roads. In terms of absolute numbers of SR crashes in the speed zones of interest, $41.1 \%$ of all police attributed SR crashes occurred on $\leq 60 \mathrm{~km} / \mathrm{h}$ roads. To date, driver sleepiness research and road safety policy have predominantly focused on high speed roads, for example, experimental driving simulator studies most often use motorway driving scenarios (e.g. Horne and Reyner 1996, Anund et al. 2008, Filtness et al. 2012). This resolute methodological focus has resulted in a lack of understanding of the role of driver sleepiness and associated impairments on low speed roads, where a substantial proportion of SR crashes occur. Therefore, it is unknown whether the research knowledge being applied to mitigate driver sleepiness is relevant for two-fifths of the SR crashes. Further research is necessary to understand the impact of sleepiness on low speed driving performance and its association with crashes.

When considering only low speed crashes, SR crashes result in more severe outcomes than did notSR crashes. This distinction of severity remains when all factors are controlled for in logistic regression, where minor injury/property damage only crashes are at lower odds of being SR-L compared with not SR-L. This result provides evidence that low speed SR crashes warrant specific investigation. This is important because they occur in densely populated areas, exposing a greater number of people to risk and have more severe outcomes than not-SR crashes on the same low speed roads. The increased prevalence of high severity outcomes associated with SR crashes has been reported by others when considering only high speed zones (Connor et al. 2002). It is likely that the higher severity of SR crashes is as a result of the failure of the driver to react, rather than due to a slowed reaction. This is consistent with observations of no signs of braking as another common feature of SR crashes (Horne and Reyner 2001). When compared to other driver impairment related crashes, e.g. those associated primarily with alcohol or drugs, it is perhaps unsurprising that SR crashes tend to have more severe outcomes. While a drunk or drugged driver 
may have a slowed reaction time, the reaction time of sleep deprived individuals is characterised by prolonged lapses, with no reaction at all (Lim and Dinges 2008). Therefore, a non-reactive sleepy driver is likely to enter a crash at the same speed they were previously traveling, without braking, as opposed to their drunk counterpart who may brake late. The greater severity of SR crashes in low speed zones may also be influenced by the greater proportion of head-on collisions. Head-on crashes have the potential to be more severe due to the input of opposing kinetic energy by both objects compared to other crash outcomes. The serious nature of SR-L crashes and the overrepresentation of head-on collision suggests that SR-L crashes should be an important focus area for improving road safety.

There was no difference in the proportion of drink drivers between SR-L and SR-H categories; however, SR-L crashes were more likely to involve alcohol above the legal limit (>0.49 BAC for open licence holders and >0.00 BAC for provisional licence holders) than were not SR-L crashes. Previous research has demonstrated that low doses of alcohol interact with sleepiness to cause greater impairment than either alone, and greater impairment than their simple additive effects would predict (Horne et al. 2003, Banks et al. 2004). The combination of sleepiness and alcohol appears to be particularly dangerous in low speed zones. However, when all other factors are controlled for in the logistic regresion analysis the relationship reverses, and the involvement of illegal BAC is at lower odds in SR-L crashes than not SR-L crashes. This suggests there may be another unknown factor that is influencing the relationship between sleep and alcohol related crashes. Futher research is needed to identify factors which influence the interaction between alcohol and sleepiness in low speed zones.

Collisions with a stationary object or running off the road have been identified as common outcomes of SR crashes (Horne and Reyner 2001). In the current analysis, the crash outcome of hitting a stationary object was more common in SR-L crashes than in SR-H crashes, and more common in SR-L crashes than not SR-L crashes. When all other factors were controlled for in the logistic regression, 
1 collision with a stationary object remained more common in SR-L crashes than in not SR-L crashes,

2 but was no longer different between SR-H and SR-L crashes. Overall, this crash outcome appears to

3 be common to both high and low speed SR crashes and a distinct feature of SR-L compared to not

4 SR-L crashes. This finding adds support to the suggestion that collision with a stationary object may

5 be considered a feature with which SR crashes could be identified (Crummy et al. 2008).

6 To further understand the nature of SR-L crashes, comparison was made to SR-H crashes. Sleep

7 crashes on $\geq 100 \mathrm{~km} / \mathrm{h}$ roads were selected as a reference group because previous work has

8 identified that SR crashes are prevalent in high speed zones (Philip et al. 2014) and most is known

9 about SR driving impairment on high speed roads as experimental research using both simulators and on-road protocols has focused on these speeds. The current work supports the value of investigating high speed SR crashes as SR crashes were found to be 7.5 times more likely on high speed roads. SR crashes also make up a greater proportion of high speed than low speed crashes. However, this distribution is influenced by the greater overall frequency of crashes on low speed roads. SR crashes on high speed roads remain a leading road safety problem which is imperative to address. Nevertheless, the current work also demonstrates that SR crashes are not confined to high speed roads. Therefore, any resources aimed at reducing the number of SR crashes should not overlook low speed roads. Low speed zones are commonly applied in highly populated areas. Therefore, for every crash which occurs in a low speed area there are a greater number of people who could potentially be impacted compared with an equivalent crash in a high speed zone.

The current work demonstrates that SR-L crashes are similar to SR-H crashes in that young (16-24y) males are over represented, and the odds of crash outcome (hitting object, head-on, rear-end, angle crash, sideswipe) are the same. This finding identifies a need to target interventions for reducing driver sleepiness towards young drivers specifically, and in all road environments. Road safety strategies for reducing driver sleepiness are often passive, and targeted at the general population e.g. road-side signage advising drivers to take a break. These interventions do not specifically target 
1 the demographic most at risk (young novice drivers), nor do they address the underlying cause of

2 sleepiness (insufficient sleep). Previous research has demonstrated that sleep loss is prevalent in

3 young people, for example, due to social (Breslau et al. 1997) and developmental (Brendel et al.

4 1990) factors. Furthermore, the driving performance of younger adults is more impaired following sleep loss than that of older drivers (Filtness et al. 2012). All of which demonstrate the importance of targeting driver sleepiness mitigation strategies towards this group.

For the majority of variables SR-L and SR-H crashes were very similar in characteristic. Three notable exceptions were, the involvement of a heavy vehicle, serious outcomes, and carrying passengers. This is likely to be a reflection of the way in which high speed roads are used, rather than an important difference between SR-L and SR-H per se. There are likely to be a disproportionate number of heavy vehicles traveling on high speed zone roads compared to low speed zone roads as freight transport often involves the movement of goods between urban areas. Therefore, it is possible that this finding is a reflection of exposure rather than an explicit difference between SR crash characteristics of low and high speed. Similarly, the greater severity of SR-H crashes is likely a reflection of the crashed vehicle having been traveling at a higher speed at the point of impact than SR-L. One countermeasure commonly proposed to mitigate driver sleepiness is to alternate between drivers (Department of Transport and Main Roads, 2010). Many of those drivers who had a SR-H crash had a passenger with them, although it is not known whether the passenger would have been able to take over driving; it is a possible option which could have reduced the chance of SR crash. Education campaigns may wish to focus on this area with an aim of empowering drivers to feel able to ask passengers to take over the driving task and to encourage passengers to offer to drive. However, it should be acknowledged that for young drivers, carrying a peer passenger can have a negative influence on safe driving behaviour (Curry et al., 2012). As young drivers are the most likely to have a SR crash, caution should be taken on the appropriateness of recommending alternating drivers as a countermeasure to sleepiness for this group. Drivers who have SR crashes on low speed roads are less likely to have the option to alternate drivers. The absence of a passenger may also 
1

2

3

4

suggest a difference in purpose of journeys which end in SR-L than SR-H crashes. For example, survey data suggests that SR-L crashes are more likely to occur during commuting (Armstrong et al. 2013). Therefore, education campaigns would have greatest chance of success if they target countermeasures which were most appropriate for the particular situation e.g. seeking alternative transport options for shift workers traveling in low speed zones.

\section{Direct comparison between SR-L and SR-H crashes demonstrated SR-L crashes to be more prevalent} than would be expected at night (10pm-6am). Time of day has a strong influence on driving performance (Lenné et al. 1997, Matthews et al. 2012), with greater impairment reported during circadian-mediated periods of low arousal. However, these time-of-day studies have been conducted using high speed environments and it is not clear whether the same variation in driving performance would be observed under the more complex, and dynamic driving scenarios common to low speed roads. Although time-of-day differences were initially apparent, when all other factors are controlled for within the logistic regression analysis, night time driving no longer has a significant influence on SR-L. Future research may wish to consider time-of-day effects in low speed environments for sleep deprived drivers and seek to understand what factors contribute towards and are protective of SR crashes. For example, there may be particular implications for shift workers who commute on these roads during night time hours.

Overall, the proportion of SR crashes (5.3\% high speed crashes, $0.7 \%$ of low speed crashes) is lower than might be expected from case control studies, which suggest that approximately $19 \%$ of all fatal and severe road crashes can be attributed to sleepiness (Connor et al. 2002). While it is possible that local safety campaigns have been effective at reducing the number of drivers who drive when sleepy, it should be noted that the most likely reason for the difference is that the current analysis was conducted on data from police data rather than a case control study. Therefore, it is likely that the current results are an underestimation of the total number of SR crashes. USA estimates suggest that SR fatal crashes may be underestimated by as much as $350 \%$, due to missing data or 
1

misclassification by attending enforcement officers (Tefft 2012). There may be several reasons for this, first, police officers lack an accurate objective measure of sleepiness and self-reported difficulty to identify sleepiness as a crash causal factor (Radun et al. 2013). Second, in a previous study we have found that of drivers who self-report having had a SR incident in the previous 5 years, only $45 \%$ report that the police were involved (Armstrong et al. 2013).

The current work does not seek to evaluate police methods for identifying SR crashes. Rather, the objective was to quantify the characteristics of SR crashes in the existing police data. However, given the reported police difficulty in identifying SR crashes (Radun et al. 2013) future research should consider how police reporting of SR crashes could be improved. For example, one approach which may assist police officers in accurately determining sleepiness would be to include in this database the mandatory collection of information estimating how long drivers have been awake, how long their last sleep period was and how long they had been driving prior to the crash. These variables are not currently recorded within the police crash database so it was not possible for them to inform this analysis. However, this does not mean that this information did not form part of the investigation when police determine the crash casual factors. Similarly, while the police may consider sleep disorders as a potential contributor to driver sleepiness, potentially clinically relevant information for sleep disorders e.g. weight and reports of snoring are not available in the analysed data set because they are not standard variables recorded in the database. The current work considers only the standard police crash investigation information held by the Queensland State Government, it does not consider the specifics of each investigation; this information is unknown to the authors.

Queensland authorities (independent to police) are aware of the potential for underestimating SR crashes and apply a proxy definition post-hoc to all crash data. This definition states that sleepiness is a contributing factor in all single-vehicle crashes on $\geq 100 \mathrm{~km} / \mathrm{h}$ speed roads which occur between $2 \mathrm{pm}$ to $4 \mathrm{pm}$ and $10 \mathrm{pm}$ to $6 \mathrm{am}$, or where a vehicle leaves the roadway with the driver not attempting to avoid the crash. The use of this definition is not considered in this work. Using a proxy 
1 definition such as this increases the proportion of crashes identified as SR; however, there is a

2 current lack of evaluations verifying the accuracy of this approach. The implications for using a proxy definition of SR crash on estimates of sleep involvement in high speed zone crashes in Queensland is discussed in our previous work (Filtness et al. in press).

The limitations of the current work should be acknowledged. All crash data were from police report. The accuracy of police at identifying the involvement of fatigue or sleepiness in each crash was not considered. There is potential for inconsistency in reporting between police officers particularly for differences between serious and non-serious crashes. Additionally, the magnitude of under reporting may not be consistent across the high and low speed zone crashes. For example, if police officers are aware that SR crashes are more common in high speed zones they may be more actively looking for this causal factor in this environment, therefore SR-L crashes may be more underestimated than SR-H. The factors used by police when identifying SR crashes were not considered. It is possible that the police use some of the characteristics examined during the analysis to inform their decision, this may introduce bias to the findings.

Serious crashes (fatal or serious injury) are attended by the Forensic Crash Investigation unit, where specially trained officers will seek detailed information about the circumstances during and prior to the crash which can include the extent of prior sleep. In contrast, enforcement officers attending non-serious crashes are not as highly trained and have fewer resources available to them than do the officers of the Forensic Crash Investigation unit. Therefore, it is possible that SR identification in less serious crashes may not be as accurate. This has implications for the finding that SR-L crashes result in more severe outcomes than not SR-L crashes. It is possible that the Forensic Crash Investigation unit who only attend serious crashes may be more likely to identify SR causal factors than the officers attending a non-serious crash. Furthermore, data are only from crashes which police attended and as such results may not be representative of crashes which are not reported to 
1

2

3

4

5

6

7

8

9

the police. Finally, the data were only from a single state; it is not known how comparable findings are to other jurisdictions.

\subsection{Conclusion}

In conclusion, this study demonstrates that driver sleepiness is not restricted to high speed, motorway driving. SR-L crashes are numerous and represent $41 \%$ of all SR crashes. While SR-L crashes have largely similar characteristics to SR-H crashes, they warrant specific investigation because they occur in densely populated areas, exposing a greater number of people to risk and are notably different to not-SR crashes occurring in low speed zones. In particular, SR-L crashes are more serious than not SR-L crashes, and are more likely to involve collision with a stationary object. Young males (16-24y) are overrepresented in SR-L crashes compared to not SR-L crashes. This age group appear to be particularly at risk of SR crash. These characteristics do not differ between SR-H and SR-L crashes, suggesting that these crash features are directly related to the presence of sleepiness and are independent of speed zone. Interventions to reduce driver sleepiness should consider specifically targeting young male drivers and emphasise the potential for SR crash in low as well as high speed areas. Previous research has demonstrated that sleepiness impairs driver performance during monotonous motorway driving; however, sleepiness is a biological need that remains with the driver as they transition between high and low speed roads. Therefore, sleepiness is still present and has the same potential to impair driving performance in low speed environments. The current focus of driver sleepiness awareness campaigns on high speed driving has the potential to mislead the general public into believing that sleepiness is not a problem in low speed zones. Without accurate sleepiness detection technologies it is vital that drivers take responsibility for their own sleepiness and take action when necessary. Experimental evidence has demonstrated that drivers are able to identify sleepiness if directed to look for it (Reyner and Horne 1998, Horne and Baulk 2004, Williamson et al. 2014). Drivers should be advised that lack of sleep will lead to sleepiness. Sleepiness will impair their driving performance and will put their safety and the safety of others at risk. They should learn to identify this risk before any and every drive. . 


\section{Acknowledgement}

2 The authors wish to thank Queensland Department of Transport and Main Roads for providing the 3 data.

4

5

6

7

8

9 


\section{References}

Åkerstedt, T., 2000. Consensus statement: Fatigue and accidents in transport operations. Journal of sleep research 9 (4), 395-395.

Anund, A., Kecklund, G., Vadeby, A., Hjälmdahl, M., Åkerstedt, T., 2008. The alerting effect of hitting a rumble strip-a simulator study with sleepy drivers. Accident Analysis \& Prevention 40 (6), 1970-1976.

Armstrong, K., Filtness, A.J., Watling, C.N., Barraclough, P., Haworth, N., 2013. Efficacy of proxy definitions for identification of fatigue/sleep-related crashes: An Australian evaluation. Transportation Research Part F: Traffic Psychology and Behaviour 21, 242-252.

Armstrong, K.A., Smith, S.S., Steinhardt, D.A., Haworth, N.L., 2008. Fatigue crashes happen in urban areas too: Characteristics of crashes in low speed urban areas. Australasian Raod Safety Research, Plicing and Education Conference. Adelaide, Australia.

Banks, S., Catcheside, P., Lack, L., Grunstein, R.R., McEvoy, R.D., 2004. Low levels of alcohol impair driving simulator performance and reduce perception of crash risk in partially sleep deprived subjects. SLEEP 27, 1063-1067.

Belenky, G., Wesensten, N.J., Thorne, D.R., Thomas, M.L., Sing, H.C., Redmond, D.P., Russo, M.B., Balkin, T.J., 2003. Patterns of performance degradation and restoration during sleep restriction and subsequent recovery: A sleep dose-response study. Journal of sleep research $12(1), 1-12$.

Brendel, D.H., Reynolds, C., Jennings, J., Hoch, C., Monk, T., Berman, S., Hall, F., Buysse, D., Kupfer, D., 1990. Sleep stage physiology, mood, and vigilance responses to total sleep deprivation in healthy 80-year-olds and 20-year-olds. Psychophysiology 27 (6), 677-685.

Breslau, N., Roth, T., Rosenthal, L., Andreski, P., 1997. Daytime sleepiness: An epidemiological study of young adults. American Journal of Public Health 87 (10), 1649-1653. 
1 Connor, J., Norton, R., Ameratunga, S., Robinson, E., Civil, I., Dunn, R., Bailey, J., Jackson, R., 2002. Driver sleepiness and risk of serious injury to car occupants: Population based case control study. Bmj 324 (7346), 1125.

Crummy, F., Cameron, P.A., Swann, P., Kossmann, T., Naughton, M., 2008. Prevalence of sleepiness in surviving drivers of motor vehicle collisions. Internal medicine journal 38 (10), 769-775.

Curry, A. E., Mirman, J. H., Kallan, M. J., Winston, F. K., \& Durbin, D. R. 2012. Peer passengers: how do they affect teen crashes? Journal of Adolescent Health, 50(6), 588-594.

Department of Transport and Main Roads. 2010. The Essential Driving Companion Department of Transport and Main Roads, Brisbane, Australia.

Department of Transport and Main Roads. 2014. Data Analysis Road Crash Glossary. Retrieved from https://www.webcrash.transport.qld.gov.au/webcrash2/external/daupage/docs/glossary.pd $\underline{f}$

Filtness, A.J., Armstrong, K., Watson, A., Smith, S.S., in press. Sleep-related crash characteristics: Implications for applying a fatigue definition to crash reports. http://dx.doi.org/10.1016/j.aap.2015.11.024

Filtness, A.J., Reyner, L.A., Horne, J.A., 2012. Driver sleepiness-comparisons between young and older men during a monotonous afternoon simulated drive. Biological psychology 89 (3), 580-583.

Forsman, P. M., Vila, B. J., Short, R. A., Mott, C. G., \& Van Dongen, H. P. 2013. Efficient driver drowsiness detection at moderate levels of drowsiness. Accident Analysis \& Prevention, 50, 341-350.

Hallvig, D., Anund, A., Fors, C., Kecklund, G., Karlsson, J.G., Wahde, M., Åkerstedt, T., 2013. Sleepy driving on the real road and in the simulator-a comparison. Accident Analysis \& Prevention 50, 44-50.

Harrison, Y., Horne, J.A., 2000. The impact of sleep deprivation on decision making: A review. Journal of Experimental Psychology: Applied 6 (3), 236. 
Herman, J., Kafoa, B., Wainiqolo, I., Robinson, E., Mccaig, E., Connor, J., Jackson, R., Ameratunga, S., 2014. Driver sleepiness and risk of motor vehicle crash injuries: A population-based case control study in fiji (trip 12). Injury 45 (3), 586-591.

Horne, J., Reyner, L., 2001. Sleep-related vehicle accidents: Some guides for road safety policies. Transportation research part F: traffic psychology and behaviour 4 (1), 63-74.

Horne, J., Reyner, L., Barrett, P., 2003. Driving impairment due to sleepiness is exacerbated by low alcohol intake. Occupational and environmental medicine 60 (9), 689-692.

Horne, J.A., Baulk, S.D., 2004. Awareness of sleepiness when driving. Psychophysiology 41 (1), 161165.

Horne, J.A., Reyner, L.A., 1996. Counteracting driver sleepiness: Effects of napping, caffeine, and placebo. Psychophysiology 33 (3), 306-309.

Lenné, M.G., Triggs, T.J., Redman, J.R., 1997. Time of day variations in driving performance. Accident Analysis \& Prevention 29 (4), 431-437.

Lim, J., Dinges, D.F., 2008. Sleep deprivation and vigilant attention. Annals of the New York Academy of Sciences 1129 (1), 305-322.

Matthews, R.W., Ferguson, S.A., Zhou, X., Kosmadopoulos, A., Kennaway, D.J., Roach, G.D., 2012. Simulated driving under the influence of extended wake, time of day and sleep restriction. Accident Analysis \& Prevention 45, 55-61.

Philip, P., Chaufton, C., Orriols, L., Lagarde, E., Amoros, E., Laumon, B., Akerstedt, T., Taillard, J., Sagaspe, P., 2014. Complaints of poor sleep and risk of traffic accidents: A population-based case-control study. PLoS one 9 (12), e114102.

Philip, P., Sagaspe, P., Lagarde, E., Leger, D., Ohayon, M.M., Bioulac, B., Boussuge, J., Taillard, J., 2010. Sleep disorders and accidental risk in a large group of regular registered highway drivers. Sleep medicine 11 (10), 973-979.

Philip, P., Sagaspe, P., Moore, N., Taillard, J., Charles, A., Guilleminault, C., Bioulac, B., 2005. Fatigue, sleep restriction and driving performance. Accident Analysis \& Prevention 37 (3), 473-478. 
1 Radun, I., Ohisalo, J., Radun, J., Wahde, M., Kecklund, G., 2013. Driver fatigue and the law from the

2

3

4

5

6

7

8

9 perspective of police officers and prosecutors. Transportation research part F: traffic psychology and behaviour 18, 159-167.

Reyner, L., Horne, J., 1998. Falling asleep whilst driving: Are drivers aware of prior sleepiness? International journal of legal medicine 111 (3), 120-123.

Sagberg, F., 1999. Road accidents caused by drivers falling asleep. Accident Analysis \& Prevention 31 (6), 639-649.

Tefft, B.C., 2012. Prevalence of motor vehicle crashes involving drowsy drivers, united states, 19992008. Accident Analysis \& Prevention 45, 180-186.

Williamson, A., Friswell, R., Olivier, J., Grzebieta, R., 2014. Are drivers aware of sleepiness and increasing crash risk while driving? Accident Analysis \& Prevention 70, 225-234. 